\title{
Water-Quality Issues Related to Uranium \\ In Situ Recovery Sites
}

Raymond H. Johnson ${ }^{1}$, James Stone ${ }^{2}$, Ryan Truax ${ }^{2}$, Martin Dangelmayr ${ }^{2}$, Paul Reimus ${ }^{3}$, and James T. Clay ${ }^{4}$

${ }^{1}$ Navarro Research and Engineering, Inc.,

Contractor to the U.S. Department of Energy Office of Legacy Management

${ }^{2}$ Department of Civil Engineering and Environmental Engineering,

South Dakota School of Mines and Technology

${ }^{3}$ Los Alamos National Laboratory

${ }^{4}$ Power Resources, Inc.

\section{Geological Society of America}

Denver, Colorado • September 25-28, 2016 


\section{Uranium Roll Front: Formation}

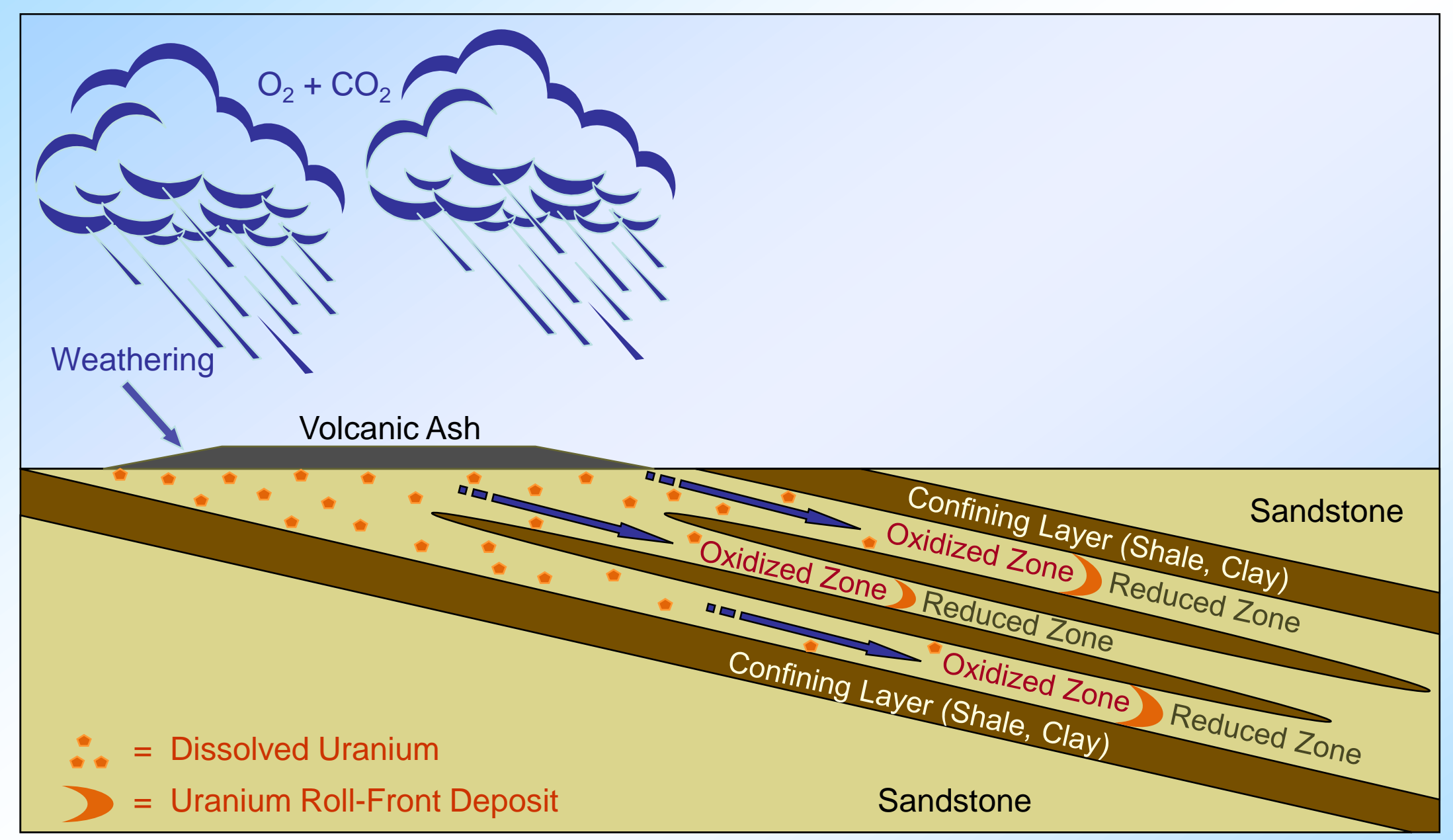




\section{In Situ Recovery (ISR) Process}

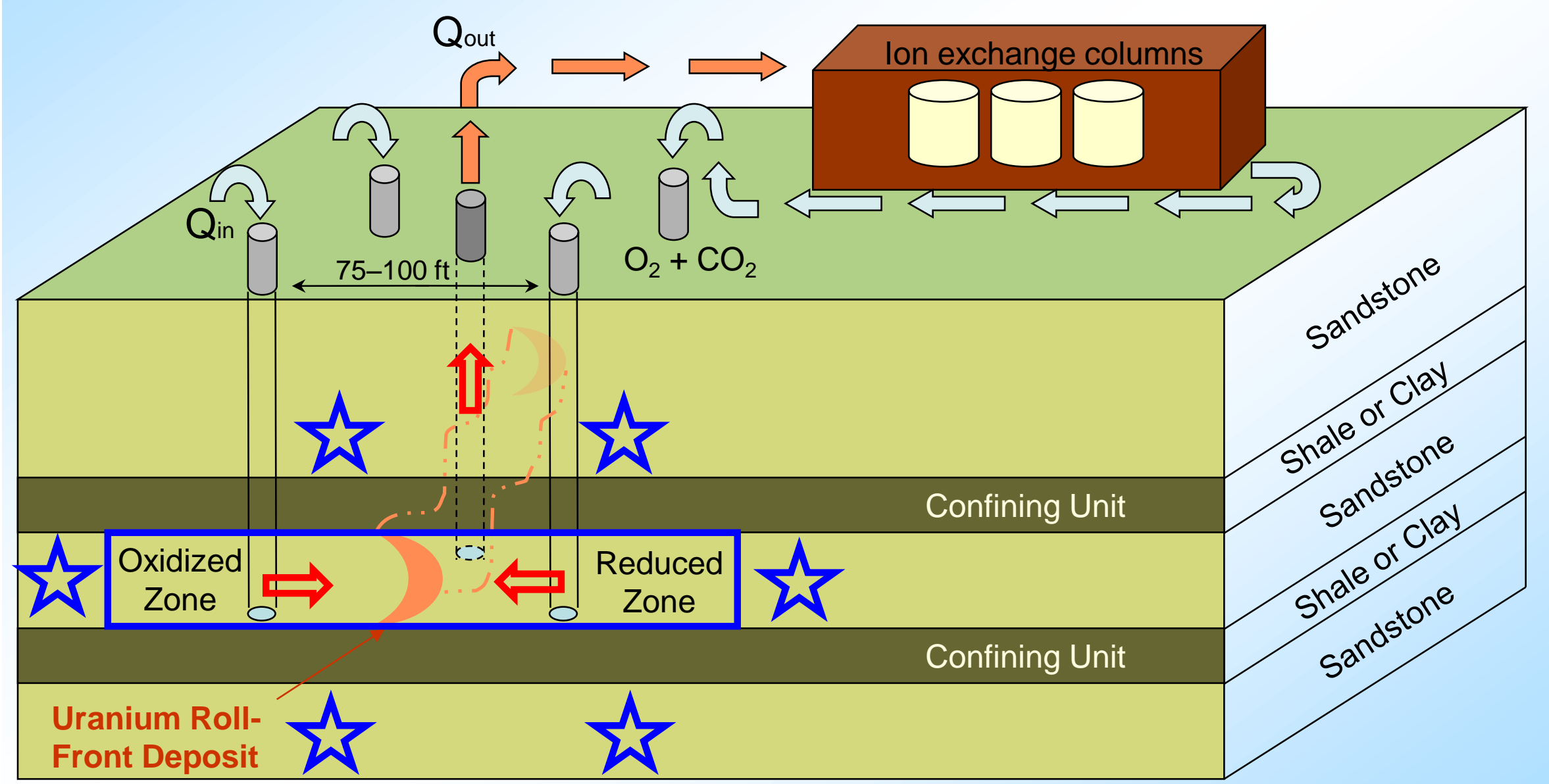




\section{Groundwater Quality Issues}

- Aquifer outside of the ISR zone could be used for:

- Agricultural irrigation

- Livestock water

- Drinking water

- U.S. Environmental Protection Agency (EPA) requirement: No change in groundwater quality outside of the aquifer exemption boundary

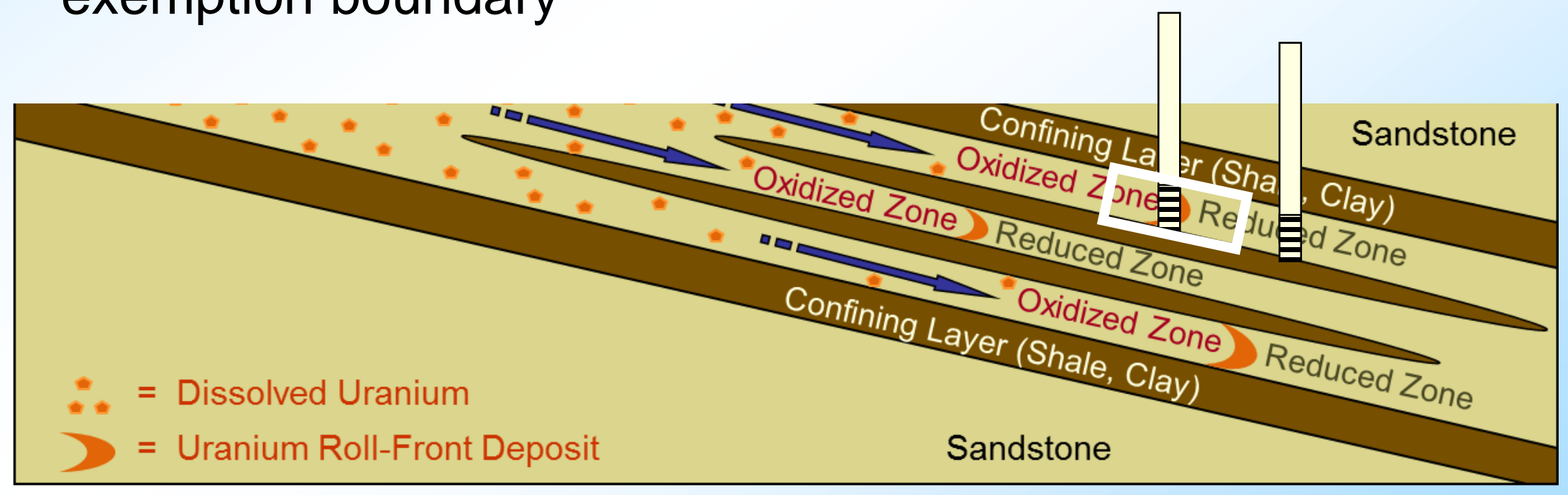




\section{Groundwater Quality Issues: Reality}

- Restoration to full, pre-ISR water quality is difficult because:

- The ISR process has significantly altered the solid phase

- Aquifer heterogeneities limit restoration efficiency

- Past ISR closures

- Some went to "class-of-use"

- Sometimes 1 year or less of monitoring

- Proposed EPA regulations

- 3 years of monitoring in conjunction with geochemical modeling

- 30 years of monitoring 


\section{Stakeholder Interest and EPA regulations}

- Determine "no impact on downgradient water quality" before ISR development or closure

- Future rock-water interaction

- Focus on downgradient water quality

- Appropriate data collection (rock and water)

- Applicable laboratory and field testing

- Predictive reactive transport modeling

- Pre-ISR data

- General site knowledge

- Core collection

- Batch testing

- Column testing

- Reactive transport modeling 


\section{Empirical Data and Parameters for Modeling}

- Contaminant sorption/desorption

- With changes in geochemistry along the groundwater-flow path due to rock-water interaction

- Contaminant precipitation/dissolution

- With changes in geochemistry along the groundwater-flow path due to rock-water interaction

- Dual porosity mechanisms (long tailing affect)

- Geologic layering

- Fractured rock, or

- Large grain size distributions 


\section{General Hydrogeology}

- Geology (rock)

- Groundwater flow directions and velocity (water)

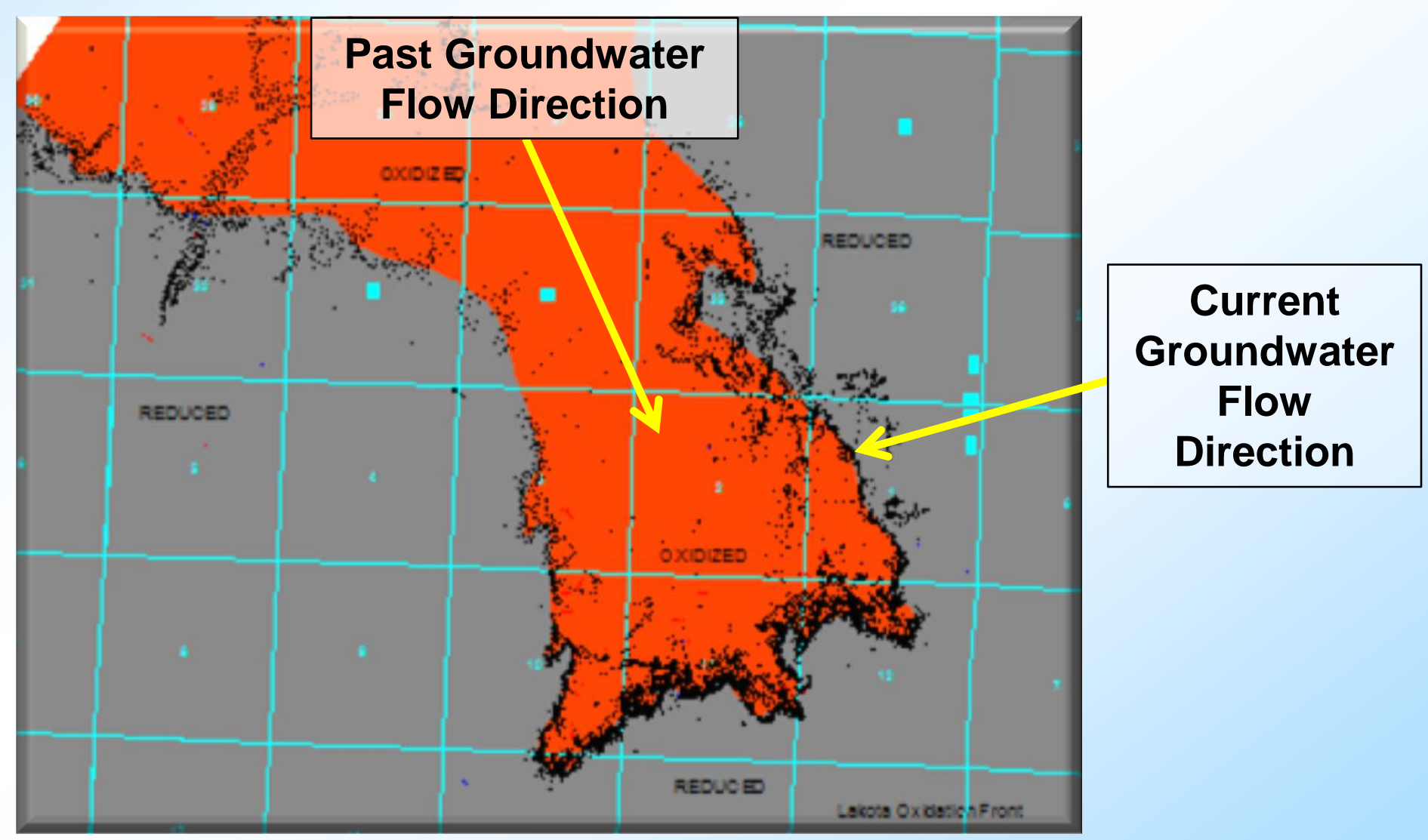




\section{Collect Core}
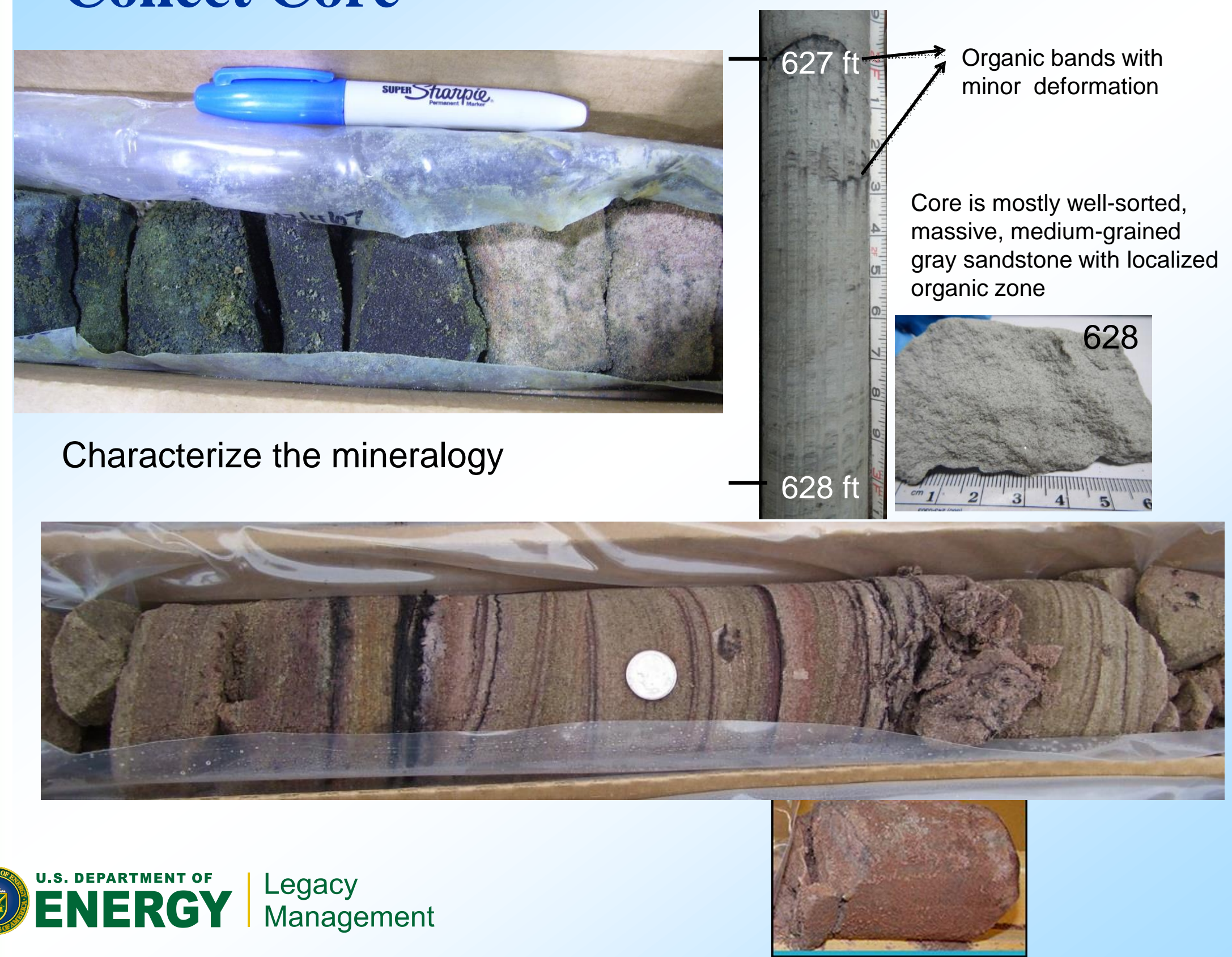


\section{Batch Testing}

Vary geochemistry to get sorption and precipitation potential

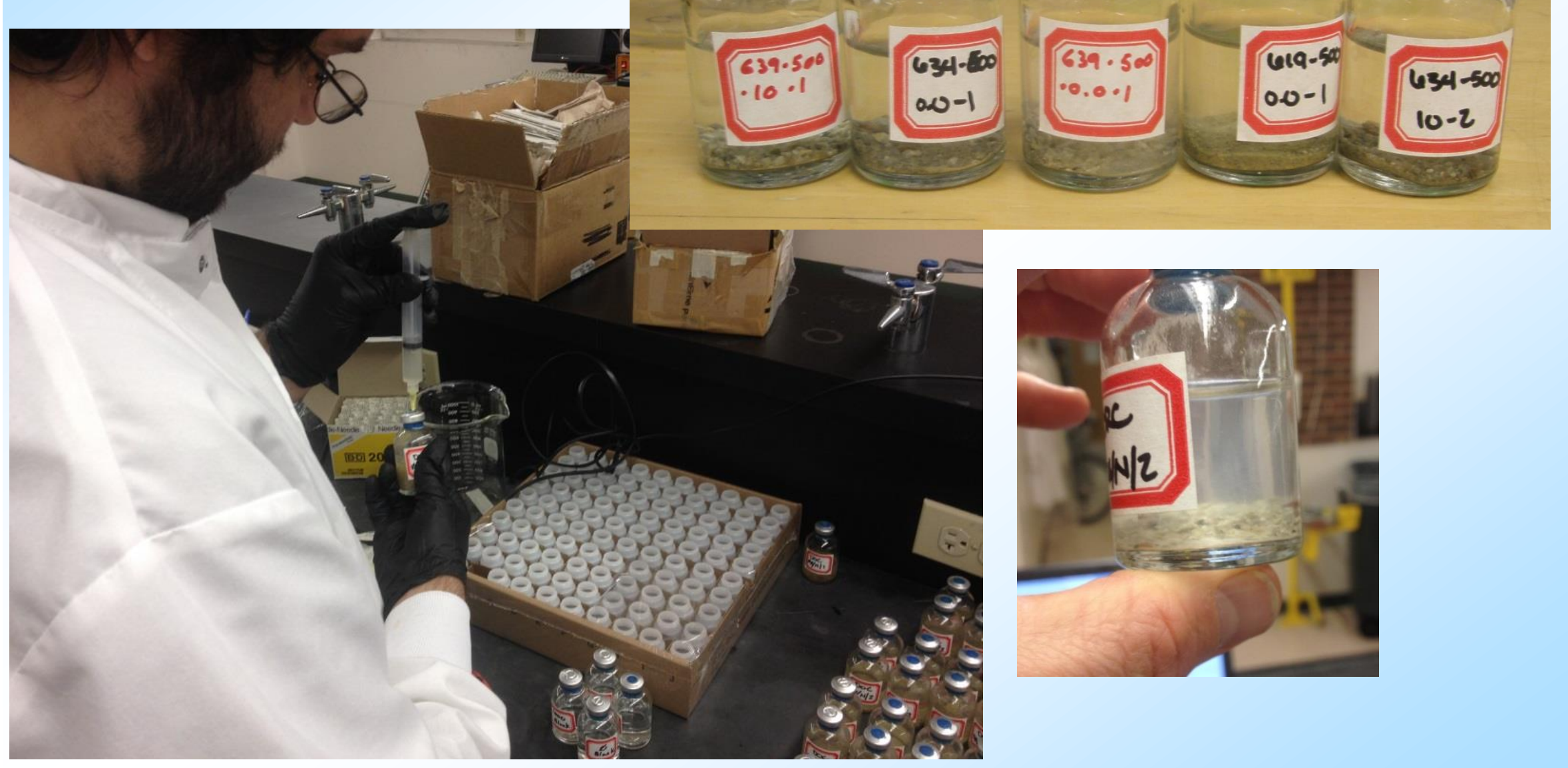




\section{Example Batch Test Results}

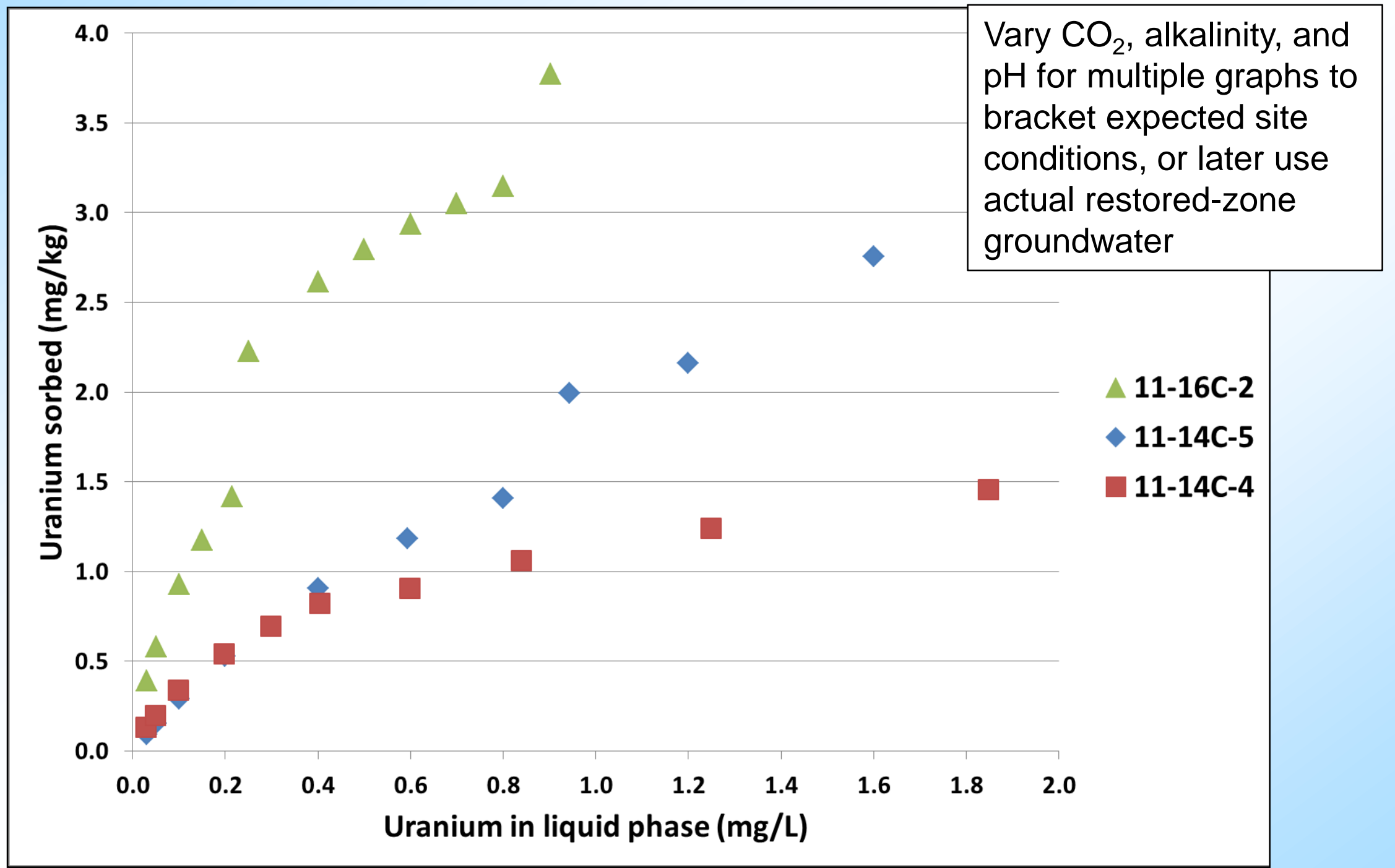




\section{Column Testing}
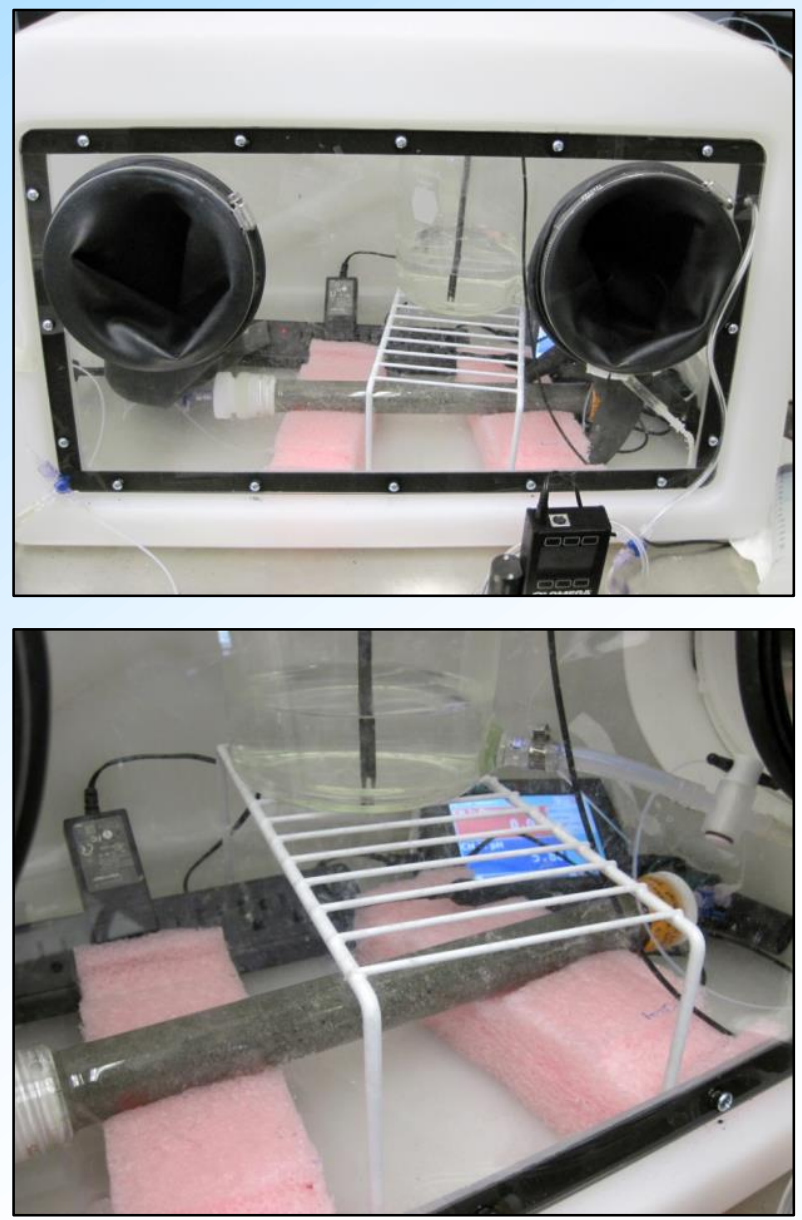

Column in a glove box at Los Alamos National Lab

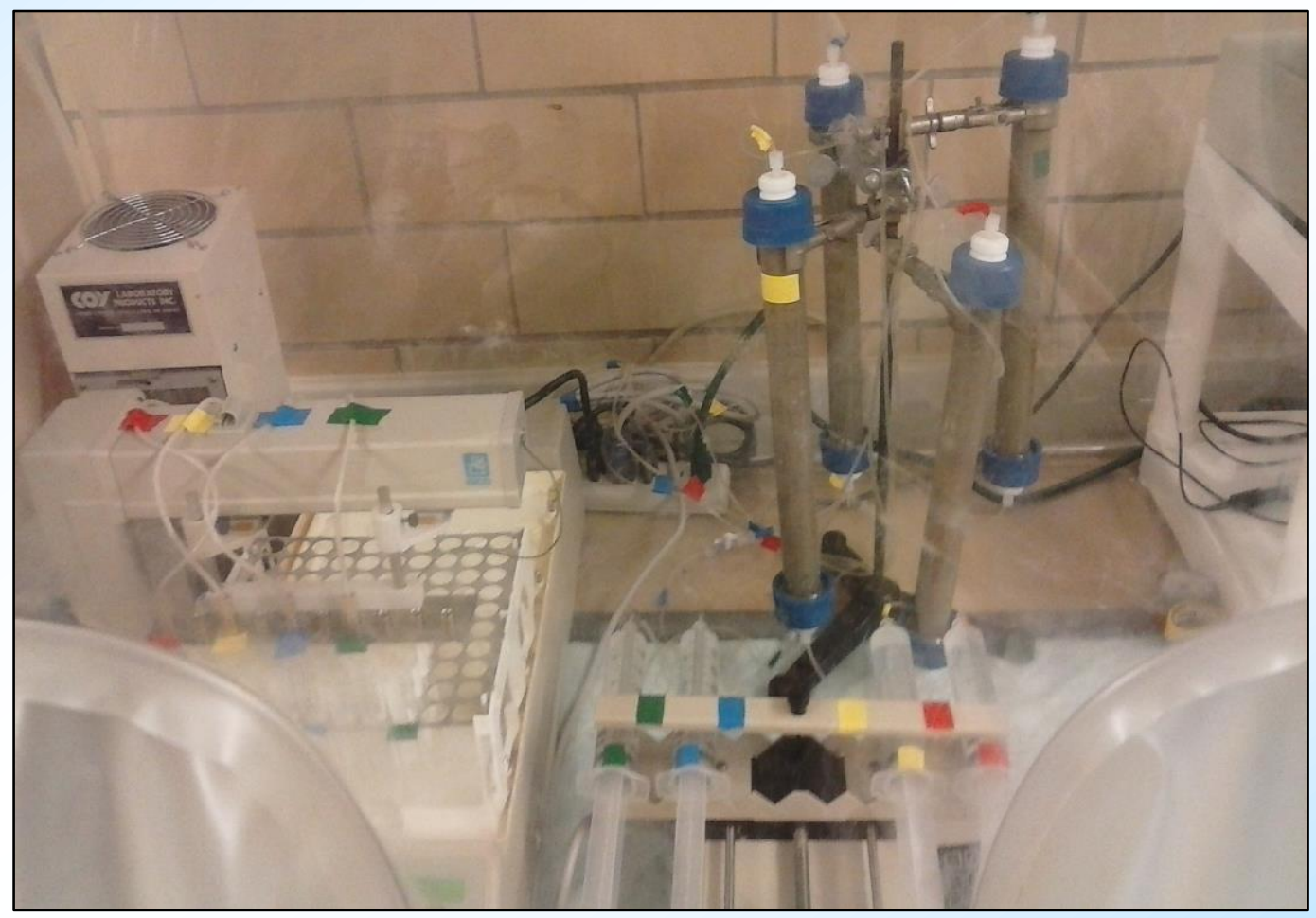

Columns in a glove box at the South Dakota School of Mines and Technology

Also, vary $\mathrm{CO}_{2}$, alkalinity, and $\mathrm{pH}$ to bracket expected site conditions, or later use actual restored-zone groundwater 


\section{Column Testing Example Results}

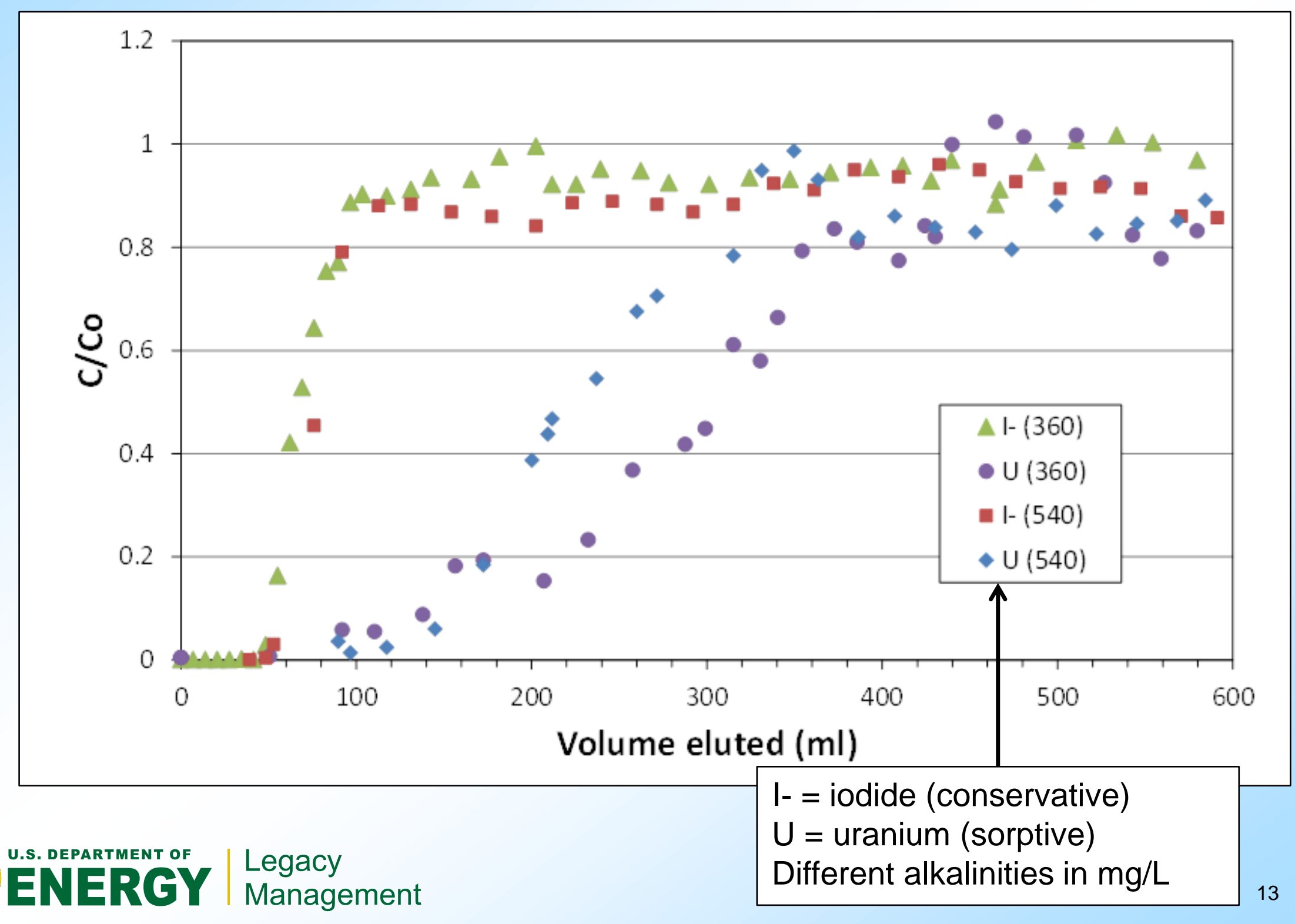




\section{Column Testing Example Results (continued)}

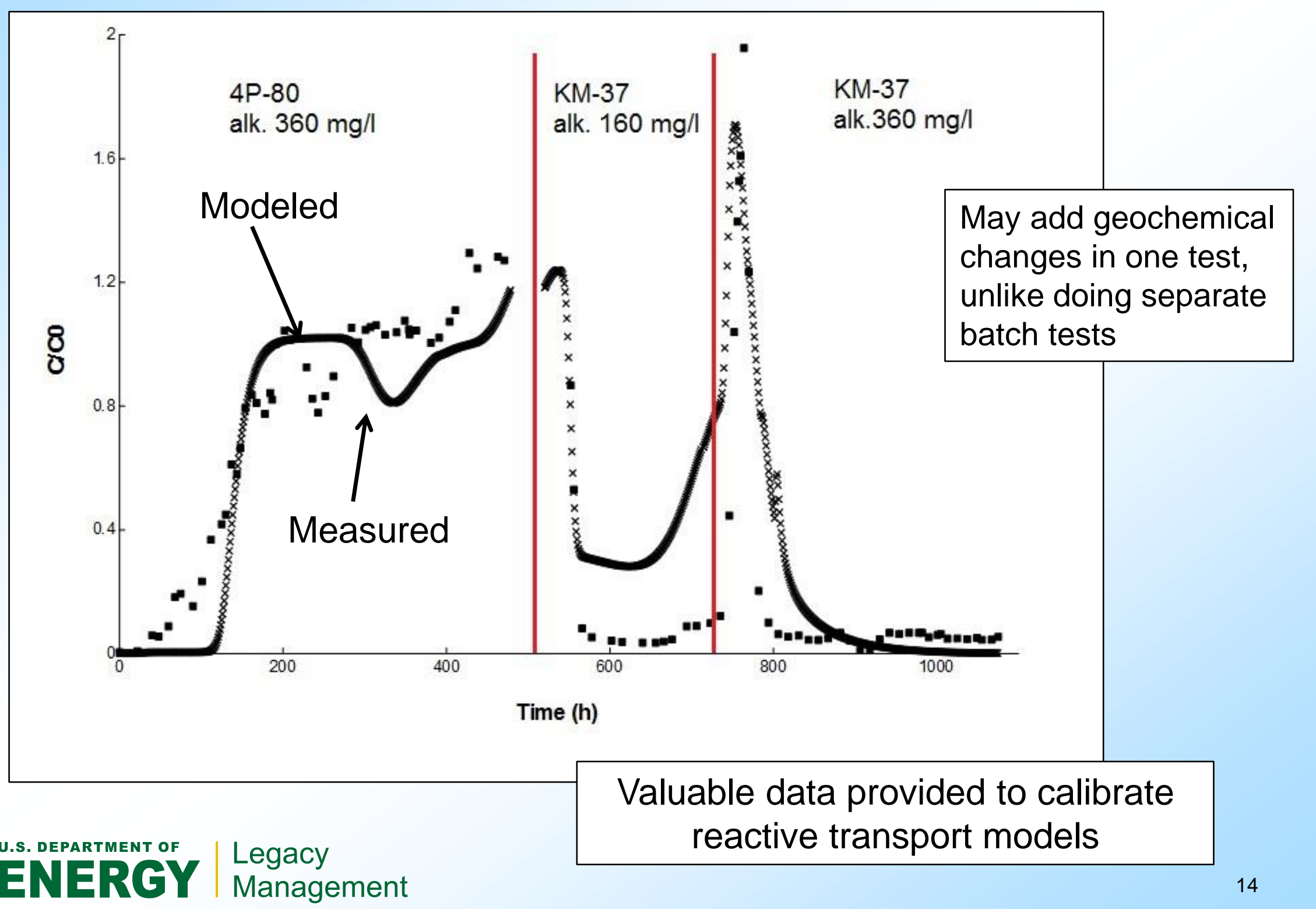




\section{Reactive Transport Modeling}

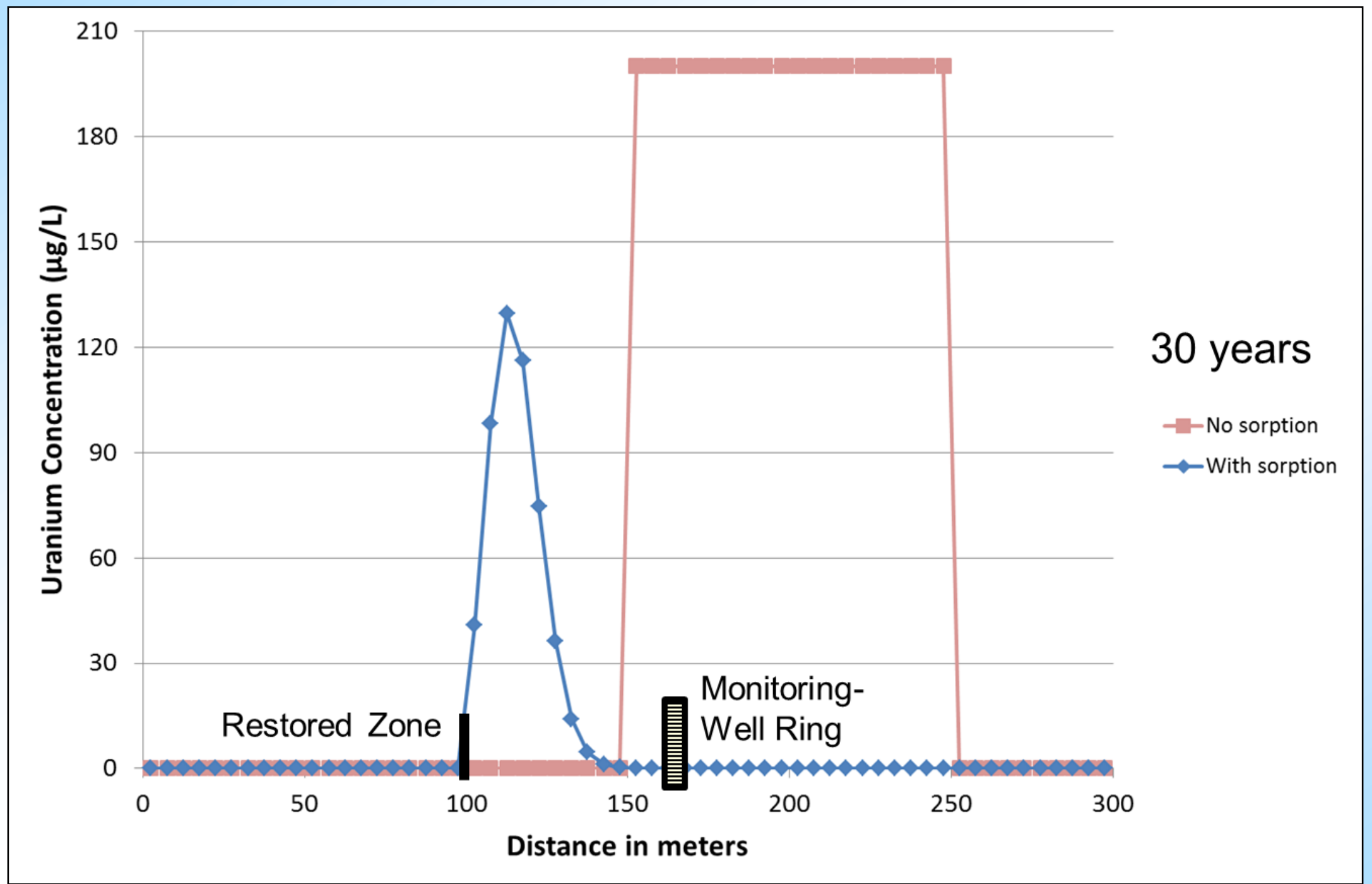




\section{Post-Restoration Data}

- Post-restoration core

- Revisit batch testing

- Revisit column testing

- Field testing

- Revisit reactive transport modeling

- Long-term monitoring data 


\section{Post-Restoration Additional Testing: Restored and Downgradient Zones}

- Test restored-zone core with background groundwater to produce an evolved background groundwater (long-term groundwater from the restored zone)

- Conduct batch and column tests on the downgradient core with:

- Unrestored groundwater (worst case)

- Final restored groundwater (real case)

- Evolved background groundwater (future case)

- Background groundwater (best case)

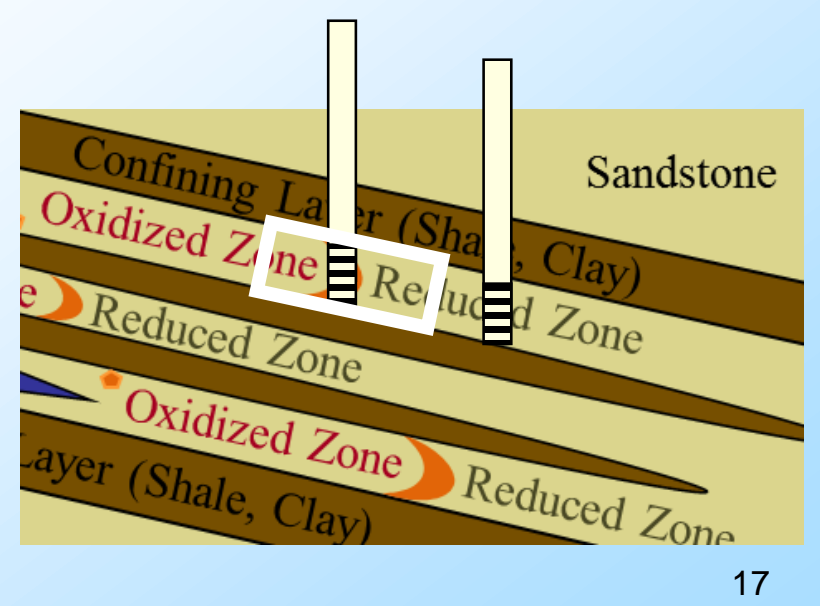




\section{Field Pilot Tests}

- Best field-scale data

- Inject and track unrestored or restored-zone water in an ore zone or downgradient zone that will be "overprinted" by future ISR

Injection Well

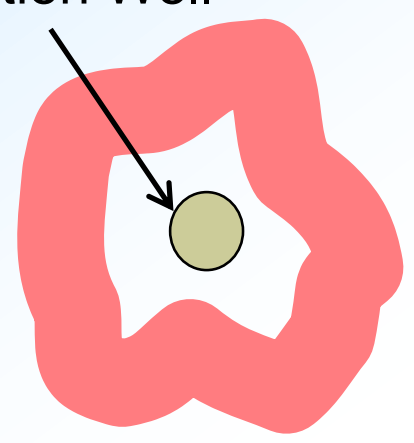

Plan View Push-Pull Test

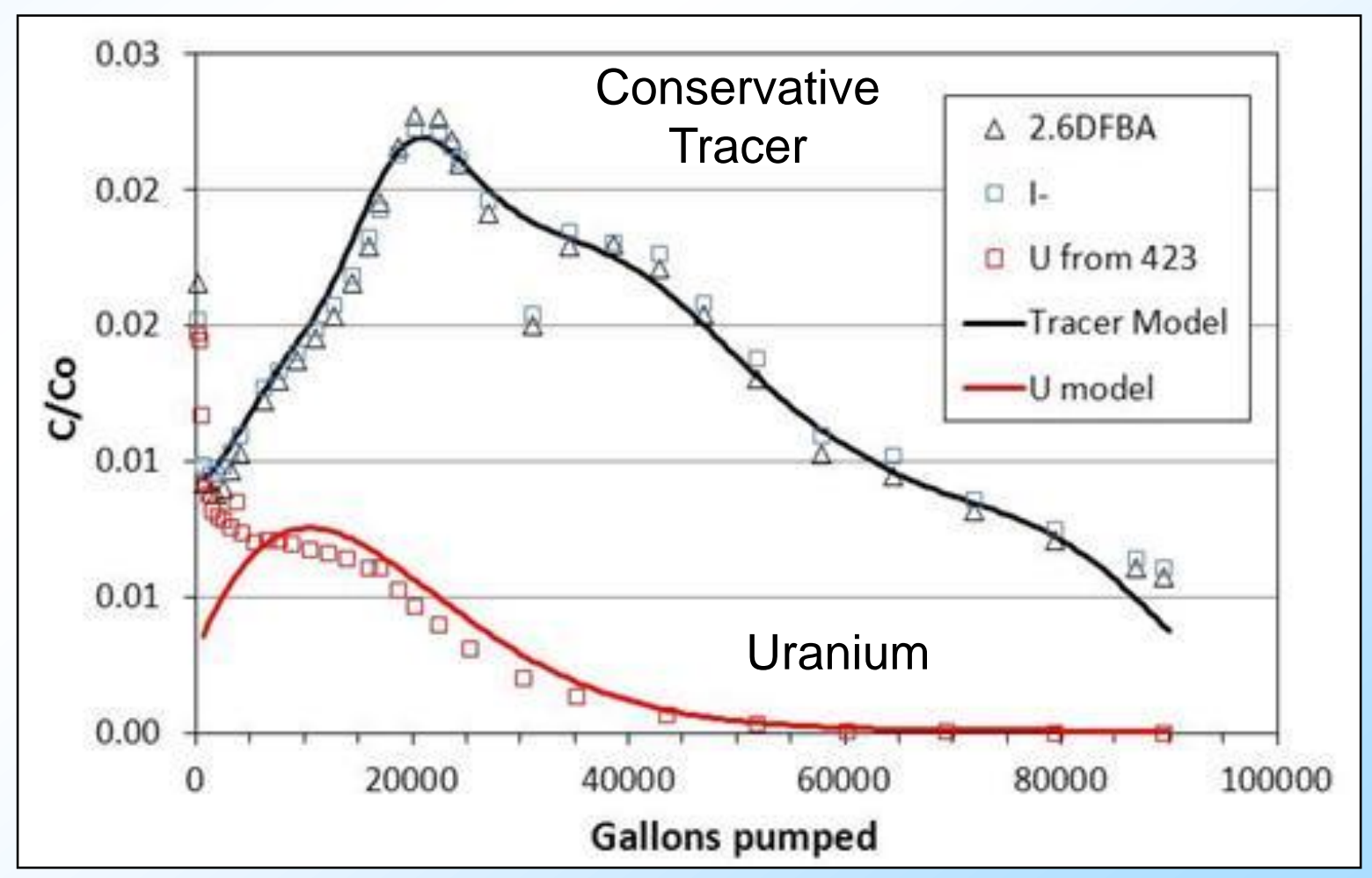




\section{Conclusions}

- Batch tests, column tests, and predictive reactive transport modeling can be done before ISR begins as part of the decision making/permitting process by bracketing possible post-restoration conditions

- Help address stakeholder concerns

- The best predictions require actual restored groundwater in contact with the downgradient solid phase

- Resulting modeling provides a range of natural attenuation rates and assists with designing the best locations and time frames for continued monitoring

- Field pilot tests are the best field-scale data and can provide the best model input and calibration data 